\title{
Censura e autotradução na era do boom latino-americano ${ }^{1}$
}

\author{
Suzanne Jill Levine* \\ Tradução de Anna Olga Prudente de Oliveira**
}

\section{O caso de Guillermo Cabrera Infante}

"E ela tentou imaginar como é a chama de uma vela depois que a vela se apaga..."2

O primeiro livro de Guillermo Cabrera Infante a ser traduzido, sua obraprima Tres tristes tigres, foi também a primeira oportunidade do autor de "closelaborate", termo que ele cunhou para falar de nossa tradução colaborativa para o inglês, língua de uma rica literatura e poder econômico. Em "The Condition We Call Exile" ("A condição chamada exílio"), Joseph Brodsky observou que escritores muitas vezes adquirem uma significação e um estilo como exilados que não possuíam como nativos em sua própria terra. ${ }^{3} \mathrm{~A}$ dissidência política, que o tornou um pária enviado ao exílio, produziria em Cabrera Infante uma revolução linguística, uma necessidade de ampliar a linguagem como escritor, para escapar do que se tornara uma prisão, seu próprio país tão amado.

\footnotetext{
${ }^{1}$ Este ensaio é uma versão revisada de uma palestra proferida em Bruxelas em 2015.

* Universidade da Califórnia, Santa Bárbara

** Universidade Federal do Paraná

${ }^{2}$ Epígrafe de TTT, referente a Alice no célebre livro de Lewis Carroll.

${ }^{3}$ Cf. The New York Review of Books (21/01/1988) em The Subversive Scribe: Translating Latin American Fiction (Dalkey Archive Press, 2009, p.20).
} 
Parte dessa ampliação linguística deu-se com a escrita em inglês, a língua estrangeira dominante em Cuba nos anos 1950 devido ao turismo e aos interesses de negócios dos Estados Unidos - e, portanto, uma língua que desempenhou um papel na revolução e em seu desdobramento, o qual levou o escritor ao exílio. Alinhado ao ethos modernista de objetividade ou "impessoalidade" do poeta, ele escreveu em inglês para criar uma distância, um espaço impessoal, não por falta de emoção, mas sim onde pudesse se afastar para conseguir suportar tanta emoção, isto é, uma nostalgia e um profundo sentimento de perda de seu país nativo.

Publicado primeiro em espanhol pela Seix Barral, principal editora na Espanha dos escritores latino-americanos mais significativos nos turbulentos anos 1960 e na década de 1970, Tres tristes tigres, ou TTT, como Cabrera Infante apelidaria o livro, ganhou o prestigioso prêmio Biblioteca Breve em 1964. Mas, antes da publicação, sob Franco, que não relaxaria sua mão de ferro sobre a Espanha até sua morte em 1975 (e mesmo depois, como evidenciado pela recente controvérsia envolvendo "O Vale dos Caídos"), o manuscrito teve que ser submetido ao crivo da censura. O livro que começou com o título Vista del amanecer en el trópico (Vista do amanhecer no trópico), e terminou sendo Tres tristes tigres (Três tristes tigres), devido ao estranho casamento da censura com a criatividade, foi transformado de uma visão do alvorecer de uma revolução nos trópicos utópicos em uma longa "Nighttown", uma noitada em Havana na véspera do fim de um mundo perdido para sempre. A última carta do censor, Robles Piquer, que liberou o livro para publicação, data de três de março de 1966 (ver HERREROOLAIZOLA, 2007). A essa altura, Vista, ou View, não mudara apenas seu título, mas, diferentemente do tigre, mudara suas listras, tanto em forma quanto em conteúdo, tanto estética quanto ideologicamente, e isso fez o incauto censor se tornar uma espécie de escritor fantasma colaborador. Ou como Alejandro Herrero-Olaizola escreve em seu bem documentado estudo The Censorship Files: Latin American Writers and Franco's Spain ("Os arquivos da censura: os escritores latino-americanos e a Espanha de Franco"), que nos fornece valiosa correspondência entre escritores e censores, Tres tristes tigres exemplifica a 
inegável continuidade de uma relação entre a autoridade externa de um regime ditatorial e o processo interno resultante da autocensura. [...] é à interação da censura oficial com sua contraparte pessoal criativa que devemos TTT e Vista del amanecer en el trópico. ${ }^{4}$ (HERRERO-OLAIZOLA, p.108)

É importante observar não só a interação entre escrita original e autotradução, tanto no original quanto na tradução de Tres tristes tigres, como também o papel da censura na prática de autotradução de Cabrera Infante, em um contexto de censura política que ele encontrou na Espanha, e ainda as sequelas traumáticas de seu apagamento e de sua expulsão de Cuba. Portanto, não é de surpreender que eu, enquanto "closelaborator" de Cabrera Infante, embora não compartilhando sua história política nem o exílio, estivesse em sintonia com a urgência de abandonar a referencialidade e o logocentrismo da linguagem. Como uma estudante americana à margem das revoluções de 1968, entrei em um questionamento radical muito característico do espírito do final dos anos 1960 - parte desse questionamento incluindo dúvidas sobre a integridade e a violência destrutiva da própria atividade revolucionária do período. (Uma figura importante da época do Vietnã, Henry Kissinger, que escapara quando jovem da Alemanha nazista, sentia a condução violenta dos protestos estudantis como uma reminiscência da SA). Além de tudo, em termos de minha própria história pessoal, os anos 1960, reavaliando a cultura popular e de massa, introduziram uma nostalgia pelos anos 1930, 1940 e 1950, os quais as pessoas da minha geração estavam vivenciando nos cinemas e na televisão. Nesse sentido, eu parecia uma boa escolha de Guillermo Cabrera Infante para colaborar em sua criação desenfreada de trocadilhos, bem no espírito de sua máxima, inspirada sem dúvida na obra de Freud sobre o chiste e o inconsciente: "Puns hide pain"5.

\footnotetext{
${ }^{4}$ N.T. Após a publicação de Tres tristes tigres, Cabrera Infante publicou o livro Vista del amanecer en el trópico, cujo título inicialmente seria usado em TTT.

${ }^{5}$ N.T. "Puns hide pain" ("Trocadilhos escondem sofrimentos"), jogo de palavras em inglês que brinca com a fonética de puns e pain. Em português, uma máxima semelhante seria: "rir para não chorar", trazendo a noção de que a graça e o riso ocultam dor ou sofrimento.
} 
Já em 1966, Cabrera Infante não era mais o editor de Lunes de Revolución, o suplemento literário do novo jornal revolucionário de Cuba do qual fora afastado após um protesto contra a censura de Fidel ao filme P.M. Entretanto, de 1962 a 1965, ele permaneceu, ao menos superficialmente, leal à causa, com um posto no consulado cubano em Bruxelas - essa foi a maneira diplomática de Fidel torná-lo invisível. Cabrera Infante estava agora divorciado da Revolução, sobretudo depois da morte de sua mãe, quando saiu de uma vez por todas de Cuba, primeiro para a Espanha, depois para a Inglaterra, com sua segunda esposa e duas filhas. Ao fazer de Londres seu lar no exílio, foi considerado um inimigo da nova Cuba e logo entrou em conflito com escritores latino-americanos de esquerda, rápidos em confrontá-lo por sua posição crítica a Fidel, entre eles, Julio Cortázar (nascido na Bélgica) e Gabriel García Márquez, que, embora politicamente divergente de Castro, permaneceu um grande amigo do ditador até que a morte os separou.

Nessa situação de conflito com seus pares literários, Cabrera Infante valorizava muito a amizade com Mario Vargas Llosa. Durante o processo de censura de TTT na Espanha, ele escreveu a Vargas Llosa que passagens políticas do livro haviam sido eliminadas. Entretanto, para os censores, havia várias passagens pornográficas, irreverentes, antimilitaristas que ainda teriam que ser eliminadas, e eles também reclamavam da falta de estrutura linear.

\footnotetext{
Escrevi às autoridades da censura, e sequer responderam à minha carta [...] Aproveitei o tempo para fazer mudanças no livro, suprimir coisas (todas as vinhetas injustificáveis, voltei ao plano original e reestruturei toda a última parte, acrescentando uma seção esboçada anteriormente, e coloquei o título que eu queria antes [...]. (Trecho da carta de Cabrera Infante a Vargas Llosa; 29 de dezembro de 1966) (HERRERO-OLAIZOLA, p.97)
}

Nesse ponto, Cabrera Infante revelou que o livro que queria escrever não era o livro que havia começado a escrever enquanto ainda vivia no âmbito da Revolução. Daí essa curiosíssima relação com os censores espanhóis, que, se por um lado, podiam ser vistos como terríveis burocratas kafkianos, eram, por outro lado, apenas escribas atrapalhados, que sem 
querer estavam do lado de Cabrera Infante, propondo mudanças que caíam como uma luva para o livro que cada vez mais ele percebia que queria escrever, eliminando inclinações e referências político-revolucionárias da versão original da obra.

Mas, como Cabrera Infante estava tentando dar forma a um livro ousadamente inovador, o censor, que reclamou da estrutura narrativa fragmentada da obra, não cooperou. O senhor Piquer estava longe de aceitar ou mesmo entender a estética de Cabrera Infante; afinal a Espanha era estritamente católica, e portanto uma linguagem sexual sem rodeios, em especial o uso de palavras de baixo calão, era inaceitável. Como Eros estava no centro pulsante da Havana que Cabrera Infante tentava recapturar em voce viva, tal censura pareceu de início um enorme obstáculo. Depois das primeiras mudanças que Cabrera Infante fez a pedido da censura, por exemplo, os censores não ficaram convencidos de que o livro mudara o suficiente; mais uma vez a obra ainda não havia sido expurgada o bastante de sua franqueza sexual, e a linguagem "forte" do original tinha que ser mais suavizada. Certos termos anatômicos explícitos precisavam ser atenuados, como amenizar tetas ou tits (tetas) em senos ou breasts (seios).

Aqui, de novo, entretanto, as restrições da censura tornaram-se um trouvaille, um achado criativo; agora o sexo precisava ser alusivo, ornado pelo humor verbal. Obscenidades escancaradas seriam substituídas pelo duplo sentido, o que se tornaria o princípio barroco em torno do qual o estilo da escrita e, consequentemente, o da tradução girariam. Além disso, os casos amorosos da mulher misteriosa Laura Diaz se tornariam um "centro de ausência" pós-moderno, que agora seria como uma elipse magnética no capítulo intitulado "Casa de los Espejos" ("Casa dos espelhos") ou "Mirrormaze" ("Galeria-de-espelhos") - e como o material alusivo nas seções psiquiátricas que, originalmente uma narrativa contínua, foram então fragmentadas ao longo do romance, vinhetas enigmáticas do passado indo ao futuro de uma história íntima, que o leitor se sente motivado a reconstruir.

Enfatizo esses detalhes para contextualizar a situação de Cabrera Infante na época em que cheguei para colaborar na tradução em 1969. Ele havia começado o trabalho vários meses antes, com a ajuda do poeta inglês Donald Gardner, cuja credencial prévia como tradutor era sua tradução da 
poesia de Octavio Paz. De novo, o contexto que menciono foi para Cabrera Infante uma dupla situação de embate, em conflito primeiramente com sua Cuba nativa, da qual havia sido exilado ao participar de um protesto contra a censura no novo regime de Fidel Castro no início dos anos 1960, e depois, na Espanha de Franco, em que ficou sujeito às regras da censura em vigor.

Comparando o manuscrito original e a versão preliminar da publicação, ambos agora nos arquivos da Princeton University, os leitores podem descobrir que Cabrera Infante não apenas despolitizou o romance, embora ainda tenha mantido referências à nação decadente de Batista (por exemplo, na história do político corrupto que engana um músico faminto), como também optou por uma "estrutura narrativa repleta de entrelaçamentos, [transformando] as narrativas mais lineares" (HERREROOLAIZOLA, p.98). Em 1966, o romance havia se tornado exuberante e taciturnamente irônico, com infindáveis trocadilhos e desvios do layout tradicional das páginas. Além disso, um novo tigre é gerado, Bustrófedon, que introduz o ato de escrever "da esquerda para a direita, da direita para a esquerda", aludindo não só ao hebraico, uma língua primeva (no mundo judaico-cristão), mas também à palavra grega, pois essa forma de escrita chamava-se boustrophedon. Esse era um personagem (cujo nome real era Walter Cassalis) que poderíamos descrever como o ideólogo linguístico joyceano do livro, o mestre de trocadilhos e paródias, que, curiosamente, traz o conteúdo político de volta à obra. Esse conteúdo aparece no centro do livro, na forma, considerada tabu, de paródias de vários escritores cubanos narrando a morte de Trotsky (incluindo José Martí, que morreu antes do assassinato de Trotsky). Uma figura controversa - no final das contas estigmatizado como traidor - na história do stalinismo, Trotsky não foi exatamente a figura histórica russa da qual Fidel desejava ser lembrado.

Em sua forma nova e final, TTT, um manifesto, um mundo textual que representa a postura e o espírito subversivos de Cabrera Infante, é também um documento de autocensura, especialmente por ter se tornado um livro mais hermético, tecido com uma linguagem secreta e referências privadas, portanto, autocensuradas. Isto é, ao usar o ocultamento como estratégia, Cabrera Infante exclui o não-especializado, ou seja, o leitor não- 
cubano. Entre as várias mudanças levadas a cabo na versão final estava a valorização da famosa cantora de bolero "La Estrella",

\begin{abstract}
tornando[-a] o centro narrativo do romance, ao passo que foram suprimidas todas as referências diretas às guerrilhas revolucionárias, e apagadas suas alusões à luta na Sierra Maestra, em uma mistura de vozes, trocadilhos e ilustrações gráficas que dão a TTT sua textura. Ao final, então, Cabrera Infante apropriou-se da noite cubana como uma representação quase nostálgica de uma Cuba perdida para um escritor exilado; e, assim, por fim, como uma resposta atrasada à censura que a Revolução fez da descrição da noite havanesa no filme P.M.. (HERRERO-OLAIZOLA, p.102)
\end{abstract}

\title{
II. O tradutor como compartilhador de segredos e sua transformação em autoescritor através da tradução
}

Durante um projeto de tradução em que trabalhei, o autor mexicano Mauricio Montiel Figueiras contou-me que, ao colaborar comigo, percebeu que estava realmente descobrindo o que de fato gostaria de escrever, precisamente ao confrontar problemas e retrabalhar a escrita na tradução. Acredito que isso aconteceu com Cabrera Infante, sobretudo porque ele tinha uma espécie de caso de amor com a língua inglesa, adorava brincar e se divertir com a língua, e fazer graça dela. $\mathrm{O}$ inglês foi um catalizador para Cabrera Infante lidar com sua condição de exilado em termos literários.

Como Dante fez com o dialeto toscano na Divina Comédia, Tres tristes tigres se transformou em Three Trapped Tigers, que foi também a primeira obra literária a tornar o cubano falado uma língua escrita, literária. TTT, com toda sua brincadeira apolítica, com todos os esforços para não falar da revolução cubana, é uma galeria de vozes, uma explosão subversiva de gírias, jogos de palavras e dislocuções joyceanas, significando um vasto mundo fragmentado em um espanhol mulato marcado pelo cubano de certas ruas em Havana, de uma região específica e de uma cidade com seus códigos secretos, mas enriquecida e polifônica com referências culturais e literárias diversas.

Nossa tradução segue o caminho subversivo do original, invadindo nomes próprios e solapando a semântica dos títulos. O censor, por todos os motivos errados, ajudou a elucidar aquilo que Infante queria dizer e o que não queria dizer: obscenidades colocadas como alusões na versão espanhola, 
e esse processo de elaboração e alusão expandido na versão em língua inglesa. Fui o instrumento perfeito para sua transformação de Karl Marx para Groucho Marx. Duplos sentidos com um único sentido eram meu pão com manteiga na adolescência, fazer piadas sobre sexo em vez de fazê-lo era o que os jovens às vezes faziam, e como uma tradutora muito jovem, na época, eu ainda estava próxima das experiências da adolescência e de vir de uma família judia assimilada, de Nova Iorque, que sentia que era preciso adequar-se à sociedade ao redor e abandonar as origens, agora de qualquer modo muito distantes. Isolamento e exílio de muitos tipos podem produzir bloqueios psicológicos e, em consequência, mecanismos compensatórios para lidar com o que você se sente incapaz de mudar. A tradução, sob essa perspectiva, pode ser uma forma de traduzir-se na escrita, tomando a escrita do outro e colocando sua marca sobre ela, transformando um ser que se sente desamparado em um indivíduo que age.

Para mim, o ato de traduzir também significou tornar-me uma crítica literária. Explorar e ter acesso aos processos internos de Cabrera Infante, por exemplo, desse brilhante malabarista da linguagem e de suas possibilidades, fez-me perceber que uma das formas mais valiosas como uma tradutora (ou tradutor) pode enriquecer sua linguagem é adotando uma consciência crítica, isto é, escolhendo com sabedoria, e talvez com um espírito de rebeldia, os autores que traduz.

\section{Referências}

BRODSKY, Joseph. The Condition We Call Exile. In: The New York Review of Books, 21/01/1988.

CABRERA INFANTE, Guillermo. Tres tristes tigres. Barcelona: Seix Barral. 1967.

CABRERA INFANTE, Guillermo. Three Trapped Tigers. Tradução: Donald Gardner e Suzanne Jill Levine com o autor. New York: Harper \& Row, 1971.

CABRERA INFANTE, Guillermo. Vista del amanecer en el trópico. Barcelona: Seix Barral. 1974. 
CABRERA INFANTE, Guillermo. View of Dawn in the Tropics. Tradução: Suzanne Jill Levine. New York: Harper \& Row, 1978.

HERRERO-OLAIZOLA, Alejandro. The Censorship Files: Latin American Writers and Franco's Spain. State University of New York Press, 2007. 